\title{
Notes on the vocalizations of Brown-cheeked Fulvetta (Alcippe poioicephala)
}

\section{Peter Boesman}

In the following we briefly analyze and compare voice of the different races of Browncheeked Fulvetta (Alcippe poioicephala). We also try to quantify the extent of any vocal differences using the criteria proposed by Tobias et al. (2010), as a support for taxonomic review. We have made use of sound recordings available on-line from Xeno Canto (XC).

Song is a short phrase of rich whistles, quite variable, with number of notes ranging from just a few to more than ten).

A comparison:

India (nominate, brucei):

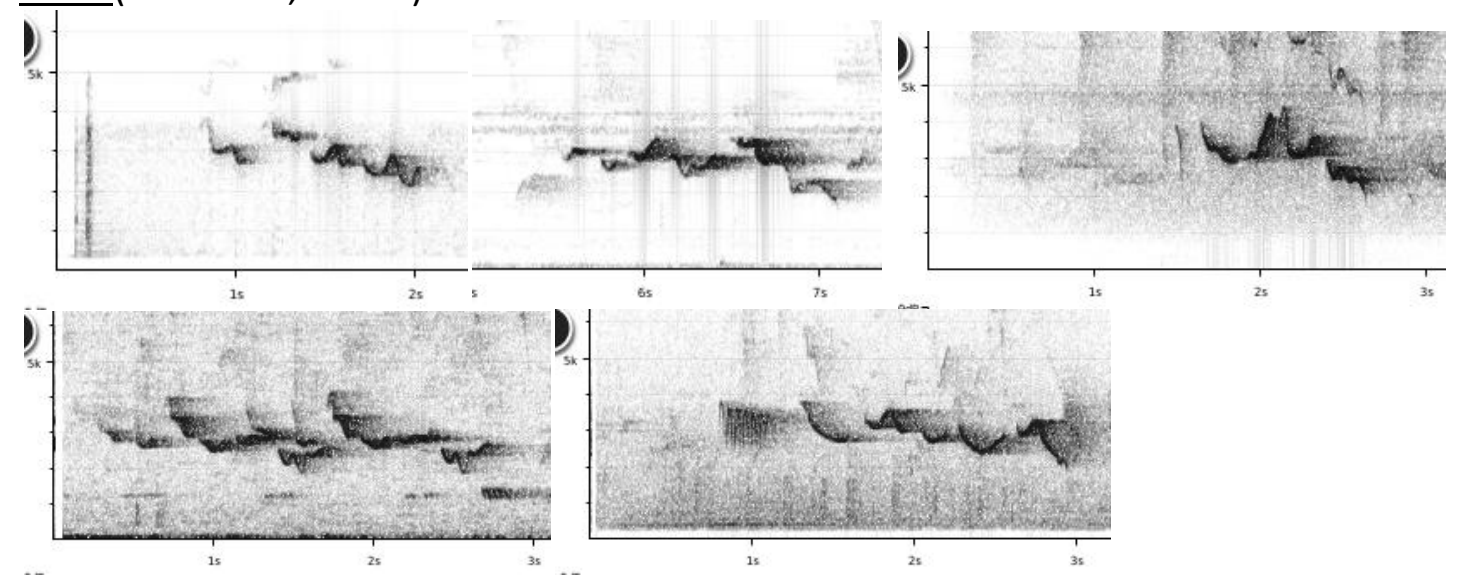

Myanmar (fusca)

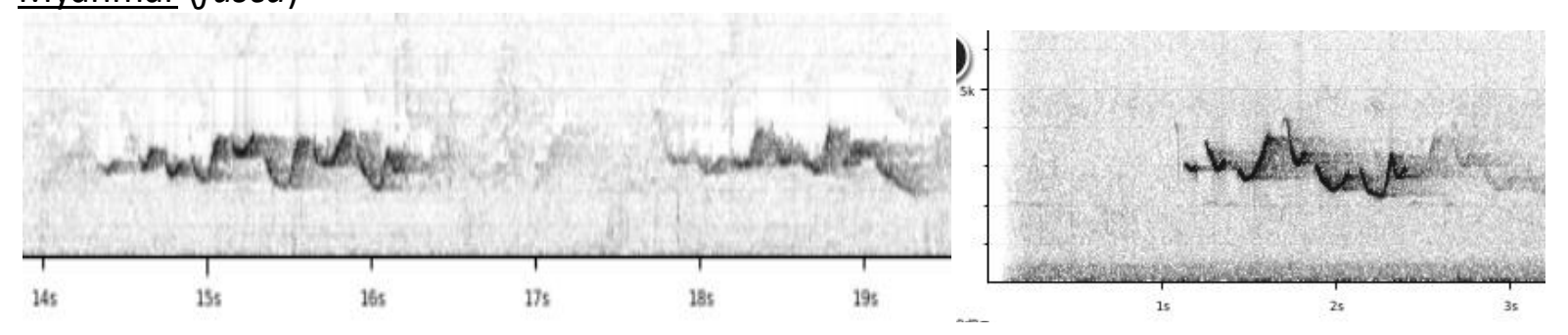

Thailand

haringtoniae

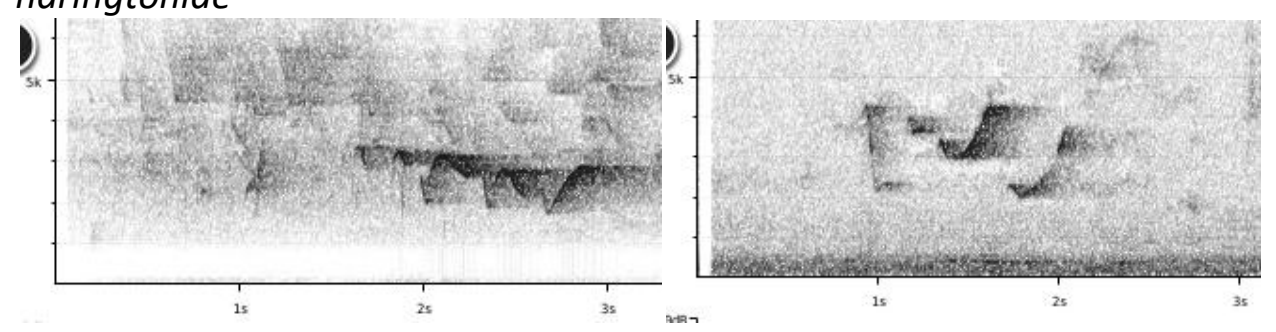



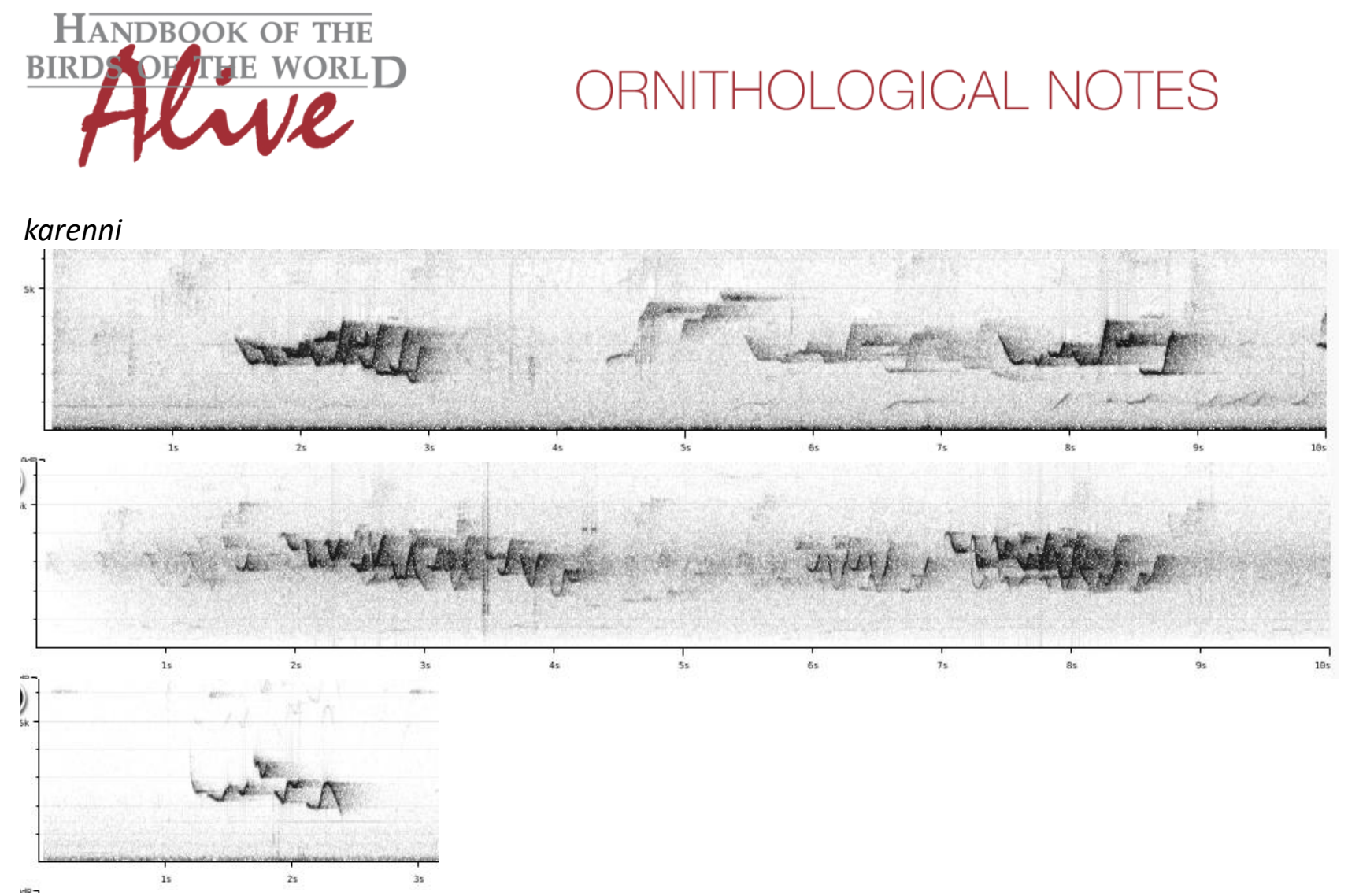

Song over its entire range is quite similar. All basic sound parameters are about the same. In India, song phrase typically has a downward trend towards the end, with final notes often downslurred. Also, the majority of notes lacks any upward inflection.

In other regions, notes often have an upward inflection and there is usually no clear downward trend of pitch in the song phrase.

There is some overlap however, and not all song phrases can be safely attributed to one of these two groups.

Vocal differences are thus rather minor, but a more detailed study would undoubtedly allow to define quantified parameters (e.g. \% of notes with end freq. lower than start freq., \% of phrases with end freq. lower than start freq., etc.) which show significant differences.

This note was finalized on 13th April 2016, using sound recordings available on-line at that moment. We would like to thank in particular the sound recordists who placed their recordings for this species on XC: Marc Anderson, Pronoy Baidya, Sander Bot, Omcar Dharwadkar, Peter Ericsson, David Farrow, Greg Irving, Vir Joshi, Pankaj Lad, Frank Lambert, Andrew Mascarenhas, Martjan Lammertink, Tero Linjama, Sushant More, Shashikant Naik, Mike Nelson, Sander Pieterse, Sudipto Roy, Vivek Puliyeri and Saurabh Sawant.

\section{References}

Tobias, J.A., Seddon, N., Spottiswoode, C.N., Pilgrim, J.D., Fishpool, L.D.C. \& Collar, N.J. (2010). Quantitative criteria for species delimitation. Ibis 152(4): 724-746. 


\section{Recommended citation}

Boesman, P. (2016). Notes on the vocalizations of Brown-cheeked Fulvetta (Alcippe poioicephala). HBW Alive Ornithological Note 273. In: Handbook of the Birds of the World Alive. Lynx Edicions, Barcelona. (retrieved from http://www.hbw.com/node/1251714 on 6 October 2016). 